\title{
Thresholds for the Effects of Pesticides on Invertebrate Communities and Leaf Breakdown in Stream Ecosystems
}

Ralf B. Schäfer, ${ }^{*}{ }^{\dagger}$ Peter Carsten von der Ohe, ${ }^{\dagger}$ Jes Rasmussen, ${ }^{\S}$ Ben J. Kefford, ${ }^{\|}$Mikhail A. Beketov, ${ }^{\perp}$ Ralf Schulz, ${ }^{\dagger}$ and Matthias Liess ${ }^{\perp}$

${ }^{\dagger}$ Institute for Environmental Sciences, University Koblenz-Landau, Campus Landau, Fortstrasse 7, 76829 Landau, Germany

${ }^{\ddagger}$ UFZ, Helmholtz Centre for Environmental Research, Department Effect-Directed Analysis, Permoserstrasse 15, 04318 Leipzig, Germany

${ }^{\S}$ Faculty of Science and Technology, University of Aarhus, Vejlsøvej 25, 8600 Aarhus, Denmark

"Centre for Environmental Sustainability, School of the Environment, University of Technology Sydney, Broadway NSW 2007, Australia

${ }^{\perp}$ UFZ, Helmholtz Centre for Environmental Research, Department System-Ecotoxicology, Permoserstrasse 15, 04318 Leipzig, Germany

\section{Supporting Information}

ABSTRACT: We compiled data from eight field studies conducted between 1998 and 2010 in Europe, Siberia, and Australia to derive thresholds for the effects of pesticides on macroinvertebrate communities and the ecosystem function leaf breakdown. Doseresponse models for the relationship of pesticide toxicity with the abundance of sensitive macroinvertebrate taxa showed significant differences to reference sites at $1 / 1000$ to $1 / 10000$ of the median acute effect concentration (EC50) for Daphnia magna, depending on the model specification and whether forested upstream sections were present. Hence, the analysis revealed effects well below the threshold of $1 / 100$ of the EC50 for D. magna incorporated in the European Union Uniform Principles (UP) for registration of single pesticides. Moreover, the abundances of sensitive macroinvertebrates in the communities were reduced by $27 \%$ to $61 \%$ at concentrations related to $1 / 100$ of the EC50 for D. magna. The invertebrate leaf breakdown rate was positively linearly related to the abundance of pesticide-sensitive macroinvertebrate species in the communities, though only for two of the three countries examined. We argue that the low effect thresholds observed were not mainly because of an underestimation of field exposure or confounding factors. From the results gathered we derive that the UP threshold for single pesticides based on D. magna is not protective for field communities subject to multiple stressors, pesticide mixtures, and repeated exposures and that risk mitigation measures, such as forested landscape patches, can alleviate effects of pesticides.

\section{INTRODUCTION}

Freshwater ecosystems are among the most threatened ecosystems in terms of species extinctions and losses in ecosystem services. One of the major stressors for these ecosystems are pesticides, which are introduced via point and nonpoint sources. ${ }^{1}$ An efficient protection of freshwater ecosystems requires the determination of a reliable threshold value for the effects of pesticides. For example, the Uniform Principles (UP) of the European Union (EU) state that for a single pesticide "no authorization shall be granted if the toxicity/exposure ratio for fish and Daphnia is less than 100 for acute exposure [...]". ${ }^{2}$ A review of mesocosm studies on the effects of single insecticides (carbamates, organophosphates, and pyrethroids) by Wijngaarden et al. $^{3}$ suggested that this safety factor would be protective. They reported that insecticide concentrations below the above-mentioned toxicity/exposure ratio of 100 that relates to a concentration of $1 / 100$ of the median effect concentration (EC50) for Daphnia magna are unlikely to cause notable effects. ${ }^{3}$ However, the joint effects of multiple stressors, including mixtures of pesticides ${ }^{4}$ are rarely considered in mesocosm studies, ${ }^{5}$ though they may influence effect thresholds. ${ }^{6}$ Indeed, a field study conducted in 20 agricultural streams showed a significant change in community structure already at an acute toxicity/exposure ratio for $D$. magna in the range of $100-1000$ for the most toxic compound. $^{7}$

Received: November 8, 2011

Revised: March 10, 2012

Accepted: March 28, 2012

Published: March 28, 2012 
Table 1. Study Regions with Number (No.) of Sites, Biological End Points Reported, Number of Pesticides Measured and Range of Toxic Units (TU) Included in This Study

\begin{tabular}{|c|c|c|c|c|c|c|c|}
\hline region & $\begin{array}{l}\text { no. } \\
\text { sites }\end{array}$ & biological end points reported & $\begin{array}{l}\text { pesticide monitoring } \\
\text { methods }\end{array}$ & $\begin{array}{l}\text { no. of pesticides } \\
\text { measured }\end{array}$ & $\begin{array}{l}\text { lowest } \log \mathrm{TU} \\
\text { reported }\end{array}$ & $\begin{array}{l}\text { highest } \log \mathrm{TU} \\
\text { reported }\end{array}$ & ref \\
\hline South Finland & 13 & $\begin{array}{l}\text { SPEAR }_{\text {abundance, }} \text { SPEARP }_{\mathrm{PM} \text { abundance }} \text { and } \\
\text { invertebrate leaf breakdown }\end{array}$ & PS and SPS & 10 & -5 & -4.3 & 17 \\
\hline Brittany, France & 16 & $\begin{array}{l}\text { SPEAR }_{\text {abundance, }} \text { SPEARP }_{\text {PM abundance }} \text { and } \\
\text { invertebrate leaf breakdown }\end{array}$ & EWS, PS, and SPS & 10 & -5 & -0.4 & 17 \\
\hline $\begin{array}{l}\text { Central } \\
\text { Germany }\end{array}$ & 20 & SPEAR $_{\text {abundance }}$ & 2 EWS & 21 & -5 & -0.7 & 7 \\
\hline $\begin{array}{l}\text { Victoria, } \\
\text { Australia }\end{array}$ & 24 & $\begin{array}{l}\operatorname{SPEAR}_{\text {pesticides }}{ }^{b} \text { and invertebrate leaf } \\
\text { breakdown }\end{array}$ & $\begin{array}{l}\text { GWS, PS, and } \\
\text { sediment }\end{array}$ & 97 & -3.5 & -0.2 & 8,19 \\
\hline $\begin{array}{l}\text { Island Funen, } \\
\text { Denmark }\end{array}$ & 14 & $\begin{array}{c}\operatorname{SPEAR}_{\text {pesticides }}{ }^{b} \text { and invertebrate leaf } \\
\text { breakdown }\end{array}$ & $\begin{array}{l}\text { EWS, GWS, and } \\
\text { sediment }\end{array}$ & 31 & -6.6 & -1.7 & 22 \\
\hline $\begin{array}{l}\text { Flanders, } \\
\text { Belgium }\end{array}$ & 7 & $\operatorname{SPEAR}[\%]^{b}$ & & $0^{e}$ & & & 18 \\
\hline North Germany & 11 & $\operatorname{SPEAR}[\%]^{b}$ & & $0^{e}$ & & & 18 \\
\hline Siberia, Russia & $6^{a}$ & $\mathrm{SPEAR}_{\text {organic }} c$ & & $0^{e}$ & & & 24 \\
\hline
\end{tabular}

${ }^{a}$ Only reference sites included (sites 3, 5, 6, 7, 9, and 10 of original publication ${ }^{24}$ ). ${ }^{b}$ Reported indicator values were calculated according to Liess and von der Ohe. ${ }^{7}$ For this study, the SPEAR pesticides values were calculated from the original data as described below. ${ }^{c}$ For this study, the SPEAR $_{\text {pesticides }}$ indicator was calculated from the original data as described below. ${ }^{d} \mathrm{PS}=$ passive sampling, SPS $=$ suspended particle sampling, EWS $=$ event-driven water sampling, GWS = grab water sampling ${ }^{e}$ Sites were considered as having no pesticide contamination. See references for details.

Beside effects on the structure of freshwater communities, pesticides can impede important ecosystem functions such as leaf breakdown ${ }^{8}$ that represents the main energy source in freshwater ecosystems beside gross primary production. ${ }^{9}$ However, to which extent effects on biota propagate to effects on ecosystem functions has been ranked as one of the most important research questions for the conservation of biological diversity. ${ }^{10}$ Theoretically, the biotic community and ecosystem functions can be linked in four ways. ${ }^{11}$ First, in a near linear way implying effects on biota would lead to a similar decline in ecosystem functions. Second, there may be functional redundancy in the community and no effects on ecosystem functions would occur up to certain thresholds. Third, the loss of most species may be compensated whereas the loss of a few so-called keystone species or ecosystem engineers would result in changes in ecosystem functions. Thus the effects depend on the identity of the species lost. Fourth, a chemical may alter the functional capacity of species and hence affect ecosystem functioning without alteration of the community. ${ }^{12}$ It is unknown which of these models applies for the relationship between effects of pesticides on biota and on ecosystem functions and whether this relationship would be universal.

Species traits have been suggested as a stressor-specific tool in ecological risk assessment ${ }^{13,14}$ as they allow for a mechanistic link between stressors and communities, even under conditions of multiple stressors. ${ }^{15,16}$ The SPEcies At Risk (SPEAR) indicator for pesticides ${ }^{7}$ relies on species traits to calculate the fraction of pesticide-sensitive species in macroinvertebrate communities. The SPEAR index has been successfully linked to pesticide toxicity and the leaf breakdown rate in field studies, while being generally discriminative toward co-occurring stressors in agricultural regions, ${ }^{7,14,17-19}$ as well as applicable over different biogeographical regions. ${ }^{17-19}$ The latter is especially important because it enables the meta-analysis of studies from different regions.

In this study, we determined thresholds for the effects of pesticides on freshwater ecosystems from a meta-analysis of field studies. Therefore, we compiled data from various field studies in different regions on the effects of pesticides on freshwater macroinvertebrate communities as detected using the SPEAR approach as well as on the ecosystem function leaf breakdown. Macroinvertebrate communities were selected as structural end point since (a) they belong to the most sensitive group of organisms to pesticides in freshwater communities, (b) trait-based approaches in freshwater ecology are most advanced for macroinvertebrates, and (c) there is a paucity of field studies on the effects of pesticides on other groups of biota. $^{20}$ In addition, we examined how effects on the structure, in terms of the fraction of pesticide-sensitive species in the communities, are related to effects on the important ecosystem function of leaf breakdown. ${ }^{20}$

\section{EXPERIMENTAL SECTION}

Selection and Description of Field Studies. The following inclusion criteria were used for the selection of field studies on the effects of pesticides: (1) at least 5 different streams monitored, (2) selection of pesticides for chemical analysis that are most likely to represent a risk to macroinvertebrates in the respective region based on recommended pesticide use information for the respective year (and region) sampled, available toxicity data for $D$. magna or results from previous monitoring programs [see $7,17,19]$ and (3) the SPEAR values or leaf breakdown rates reported. In addition, we included reference sites from studies, where SPEAR values were reported (Table 1). We focused on studies reporting the traitbased SPEAR indicator, because in contrast to taxonomical data this indicator has been demonstrated to be applicable over different biogeographical regions. ${ }^{17,18}$ However, we are not aware of other studies that met the first two criteria and presented macroinvertebrate community data to assess the effects of pesticides. For example, one study encompassing 29 different streams $^{21}$ was not included since only sediment concentrations for a limited set of pesticides were reported and the total sediment concentration of the monitored pesticides was used as a proxy for nonmonitored pesticide concentrations. Overall, 8 studies conducted between 1998 and 2010 (study duration between 2.5 and 36 months) with a total of 111 sites were included in the present study, of which 6 studies were conducted in different regions of Europe, and a study in each of Australia and Siberia (Table 1). Except for reference sites which were predominantly located in forested areas, the sites in the studies were located in agricultural areas. The sites were 
selected to not receive discharge from wastewater treatment plants, industrial facilities or mines in order to exclude the input of toxicants other than pesticides. The pesticide monitoring was adjusted (1) to capture episodic runoff events and (2) to the properties of the pesticides selected for chemical analysis in the particular study. The selected pesticides varied among the study regions due to differences in crops, pests and authorized pesticides (Table 1).

Data preparation. Environmental concentrations of pesticides were scaled to acute effects of $D$. magna calculating Toxic Units $(\mathrm{TU})^{25}$ by dividing the compound concentration with the respective 48-h median effect concentration (EC50) for D. magna. Dose-response modeling was used to evaluate the relationship between TU and SPEAR, which represent pesticide toxicity and community change, respectively. The TUs used here were given as the maximum TUs of all pesticides across samples per site in the original studies and were reported to have similar explanatory power for biotic end points as the sum of TUs of all pesticides across each or all samples per site. ${ }^{7,19,26}$ The maximum TU represents the simplest approach because the estimated pesticide toxicity relies solely on the most toxic pesticide concentration observed per site, whereas all pesticide concentrations per sample or site contribute to the calculation of the sum of TU. Carbamate and organophosphate insecticides and several fungicides were predominantly responsible for the maximum $\mathrm{TU}$ in the sites (Supporting Information Table S1).

We used the modified version of the original SPEAR indicator ${ }^{7}$ as described in Schäfer et al. ${ }^{17}$ (therein referred to as SPEAR $_{\mathrm{PM} \text { abundance }}$ ) to compare the indicator values between different biogeographical regions. For terminological clarity, we

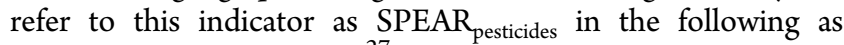
suggested by Beketov et al. ${ }^{27}$ For sites for which this version of the SPEAR indicator was not reported (Table 1), we calculated the indicator according to:

$$
\operatorname{SPEAR}_{\text {pesticides }}=\frac{\sum_{i=1}^{n} \log \left(x_{i}+1\right) y}{\sum_{i=1}^{n} \log \left(x_{i}+1\right)}
$$

where $n$ is the number of taxa observed in a sampling site, $x_{i}$ is the abundance of taxon $i$ and $y$ is 1 if taxon $i$ is classified as Species At Risk (SPEAR) regarding the traits "physiological sensitivity" and "dispersal capacity", otherwise 0 . The trait data used were derived from the database associated with the SPEAR online calculator (http://www.systemecology.eu/ SPEAR/index.php).

To characterize the propagation of effects from pesticidedriven structural changes to ecosystem functions, the response of the invertebrate-driven leaf breakdown rate $\left(k_{\text {invertebrate }}\right)^{28}$ to

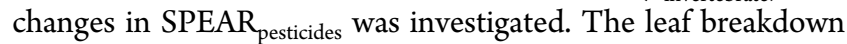
rate is not stressor-specific and hence responds to different environmental conditions. ${ }^{29}$ In contrast to species traits, ${ }^{30}$ $k_{\text {invertebrate }}$ varies over biogeographical regions and would not be expected to be similar across sites without pesticide contamination because of the influence of other environmental gradients. ${ }^{31}$ Indeed, no relevant pesticide toxicity and only

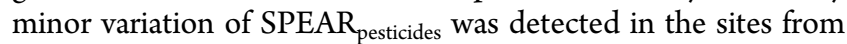
South Finland, whereas the invertebrate leaf breakdown rate varied strongly between sites in response to temperature. ${ }^{17}$ Since the aim was to examine the link between pesticide-driven community change and invertebrate leaf breakdown rate, these sites were not considered for further analysis. The invertebrate leaf breakdown rates from the French, Danish and Australian streams (Table 1) were not comparable as leafs of different tree species were employed. Therefore, the \% change in the leaf breakdown rate $k_{\text {invertebrate }}$ was calculated for each data set by dividing all values for $k_{\text {invertebrate }}$ by the maximum value obtained from individually fitted models for $k_{\text {invertebrate }}$ as explained by $\operatorname{SPEAR}_{\text {pesticides }}$ (see below). We used the maximum value from the models fitted with all data points instead of the maximum value for $k_{\text {invertebrate }}$ from the respective raw data in order to avoid undue influence of a single data point.

Data Analysis. Before analysis the data were divided into sites with and without forested upstream sections, as defined in the original publications, and analyzed separately (Table 1). This was done because the presence of forested upstream sections was demonstrated to alleviate the effects of pesticides on the macroinvertebrate community as indicated by SPEAR $_{\text {pesticides. }}{ }^{7,17,26} \mathrm{~S}$-shaped dose-response curves with TU as concentration and $\mathrm{SPEAR}_{\text {pesticides }}$ as response variable were computed using two-parameter log-logistic, Weibull I and Weibull II models with the upper limit fixed to the arithmetic

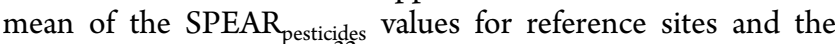
lower limit fixed to $0,{ }^{32}$ representing the lowest possible indicator value. In addition, linear, quadratic, and cubic regression models were computed to check for the fit of more parsimonious models. The best-fit model among the sshaped dose response models and the polynomial regression models was selected using the Bayesian Information Criterion (BIC). If a s-shaped dose-response curve represented the bestfit model, we calculated the effect concentration (EC) for the percentage $(\mathrm{p})$ of reduction in $\mathrm{SPEAR}_{\text {pesticides }}$ for $p=10,50$ and $90 \%$. In addition, the $\mathrm{p}$ value was computed for the EC related to the $\log \mathrm{TU}$ of -2 that is equal to the safety factor of 100 , employed in the UP of the EU. Moreover, we derived the lowest concentration at which significant differences $(\alpha=0.05)$ to reference sites occur in the best-fit dose-response model using 95\% confidence intervals. Technically, we determined the lowest concentration for which the $95 \%$ confidence interval of the fitted model did not overlap with the 95\% confidence interval for the reference sites. Several of the original studies assigned $\log$ TUs of either -5 or -4 to sites where no pesticides were found assuming that this would represent the minimum $\log \mathrm{TU}$ for which no pesticide effects would occur (Table 2). Since the minimum TU influences the dose-

Table 2. Estimated Effect Concentrations (EC) in Terms of $\log$ TU for $p=10 \%, 50 \%$, and $90 \%$ Reduction in SPEAR $_{\text {pesticides }}$ for the Models with and without Forested Upstream Sections (FUS and WFUS, Respectively) and with a Minimum $\log$ TU of -5 (low min.) or -4 (high min.)

\begin{tabular}{ccccc}
\multicolumn{5}{c}{ estimated EC (in log TU) } \\
\cline { 2 - 5 }$p$ & FUS low min. & FUS high min. & WFUS low min. & WFUS high min. \\
10 & -3.6 & -2.9 & -4.2 & -3.5 \\
50 & -1.7 & -1.4 & -2.5 & -2.1 \\
90 & -0.4 & -0.4 & -0.6 & -0.6 \\
\hline
\end{tabular}

response modeling, all analyses were conducted for both minimum reported TUs, that is, we assigned either a log TU of -5 or -4 to all sites with no pesticide detections. To confirm the results of the dose-response modeling, analysis of variance (ANOVA) with a priori treatment contrasts was used to identify significant differences in SPEAR pesticides $_{\text {values between }}$ reference sites and groups of contaminated sites in terms of TU. The class boundaries of $\log \mathrm{TU} \leq-3.5$ (reference sites), 

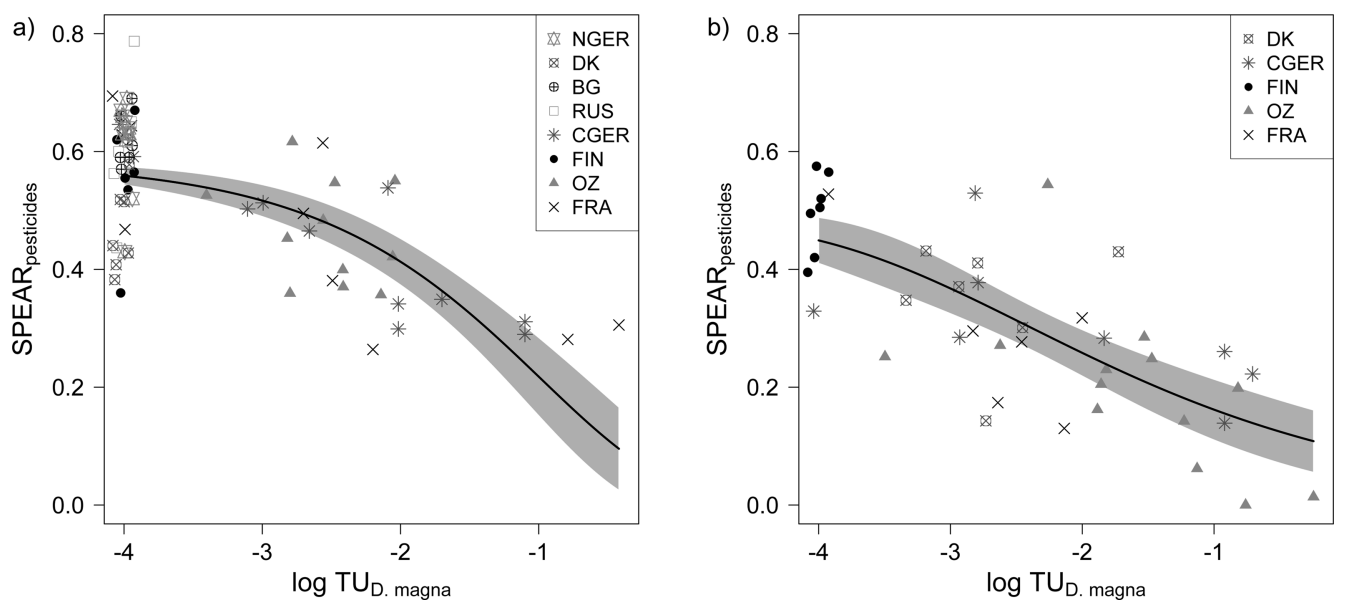

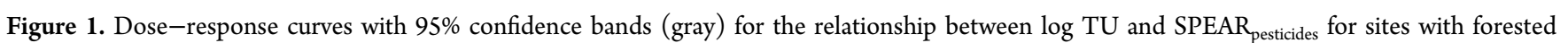
upstream sections (a) and for sites without forested upstream sections (b). Reference sites were assigned a minimum log TU of -4 . Random noise (0.00002) was added (jittering) to the TU values in order to show all data points in the plot. This affected primarily the sites with minimum TUs.

$-3.5<\log \mathrm{TU} \leq-2.5$ (lightly contaminated sites), $-2.5<\log$ $\mathrm{TU} \leq-1.5$ (moderately contaminated sites) and $\log \mathrm{TU}>$ -1.5 (highly contaminated sites) were selected in order to have similar class widths and at least 5 observations in each class. A similar classification was used in the study of Schäfer et al. ${ }^{17}$

For the examination of the propagation of effects of pesticides on ecosystem functions, the relationship between the invertebrate-driven leaf breakdown rate $\left(\% k_{\text {invertebrate }}\right)$ and $\mathrm{SPEAR}_{\text {pesticides }}$ was modeled using s-shaped dose-response models and polynomial regression models as described above, except that three-parameter s-shaped dose response models were fitted since no upper limit could be fixed. First, the modeling was done separately for each country, because in the original studies this relationship had only been examined for the sites from Brittany, France. Subsequently, the data were modeled jointly. For best-fit linear regression models, significance of the slope was tested with the $t$ test and in the case of data from different countries, analysis of covariance (ANCOVA) was used to detect significant differences between slopes and intercepts from the countries. ANOVA, ANCOVA and linear regression models were checked for normal distribution of residuals, homoscedasticity and unusual observations. ${ }^{33}$ All computations and graphics were created with the free and open source software $\mathrm{R}$ (version 2.13.1 for Mac OS X, 10.6.8) $)^{34}$ including supplemental packages such as "drc" for dose-response modeling.

\section{RESULTS}

Weibull I and II as well as log-logistic models were identified as best-fit dose-response models for TU and SPEAR pesticides (Supporting Information Table S2). The estimated $\mathrm{EC}_{10}$ for the different models ranged from a $\log \mathrm{TU}$ of -2.9 to a $\log \mathrm{TU}$ of -4.2 depending on a) the availability of forested upstream sections and $b$ ) which minimum TU was assigned (Table 2). The estimated $\mathrm{EC}_{90}$ were identical for the two minimum TUs (Table 2). For an EC related to a log TU of -2 , the fraction of species at risk in the communities in terms of abundance was reduced by $27 \%$ and $41 \%$ in sites with forested upstream sections for models with a minimum $\log \mathrm{TU}$ of -4 and -5 , respectively (Figure 1, Figure S1). In sites without forested upstream sections, this EC corresponded to $54 \%$ and $61 \%$

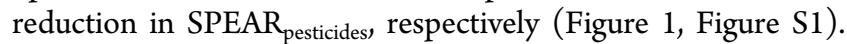
Significant differences (nonoverlapping 95\% confidence inter- vals) to reference sites were observed for $\log \mathrm{TUs} \geq-3$ and -3.5 in sites with forested upstream sections and for log TUs $\geq$ -3 and -3.6 in sites without forested upstream sections when assigning a minimum $\log \mathrm{TU}$ of -4 and -5 , respectively. Similar results were obtained for the ANOVAs, in which all sites in classes with a $\log \mathrm{TU}>-3.5$ exhibited a significant difference (all $p<0.01$ ) to reference sites (Figure 2).

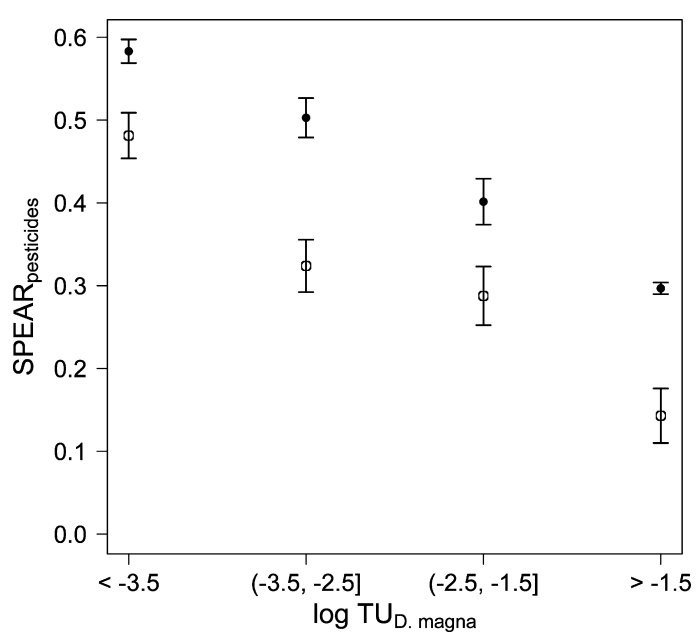

Figure 2. Arithmetic mean of $\operatorname{SPEAR}_{\text {pesticides }}$ values with standard errors for different classes of toxic units (TU). The sampling sites were divided into sites with forested upstream sections (filled points) and sites without forested upstream sections (open points). Sample sizes of the different classes were 44 and 9 sites with a $\log \mathrm{TU} \leq-3.5,10$, and 12 sites with $-3.5<\log \mathrm{TU} \leq-2.5,12$, and 11 sites with $-2.5<\log$ $\mathrm{TU} \leq-1.5$ and 4 and 9 sites with $\log \mathrm{TU}>-1.5$ for sites with forested upstream sections and sites without forested upstream sections, respectively. All classes with TUs $>-3.5$ were significantly different $($ all $p<0.001)$ to reference sites in ANOVA with treatment contrasts.

The linear models exhibited the best-fit for the relationships between $\% k_{\text {invertebrate }}$ and SPEAR pesticides, $_{\text {, except for sites from }}$ Brittany, France, for which a Weibull II model yielded a slightly better fit (Supporting Information Table S2). However, the slope for linear regression models was only significant for the sites from Victoria, Australia $\left(r^{2}=0.46, p<0.001, n=23\right)$ and Brittany, France $\left(r^{2}=0.87, p<0.001, n=11\right)$, but not for the 
sites from Denmark $\left(r^{2}=0.09, p=0.31, n=13\right)$, for which no plausible relationship between $\operatorname{SPEAR}_{\text {pesticides }}$ and $\% k_{\text {invertebrate }}$ could be established (data not shown). The sites from Denmark were not included in the joint dose-response modeling, because the aim was to derive a joint relationship between SPEAR pesticides $_{\text {and }} \% k_{\text {invertebrate. The best-fit model for }}$ the joint data from France and Australia was linear (Supporting Information Table S2) and exhibited a good fit between \% $k_{\text {invertebrate }}$ and SPEAR pesticides $\left(r^{2}=0.51, p<0.001, n=34\right)$ (Figure 3). In ANCOVA, the intercepts for data from Brittany

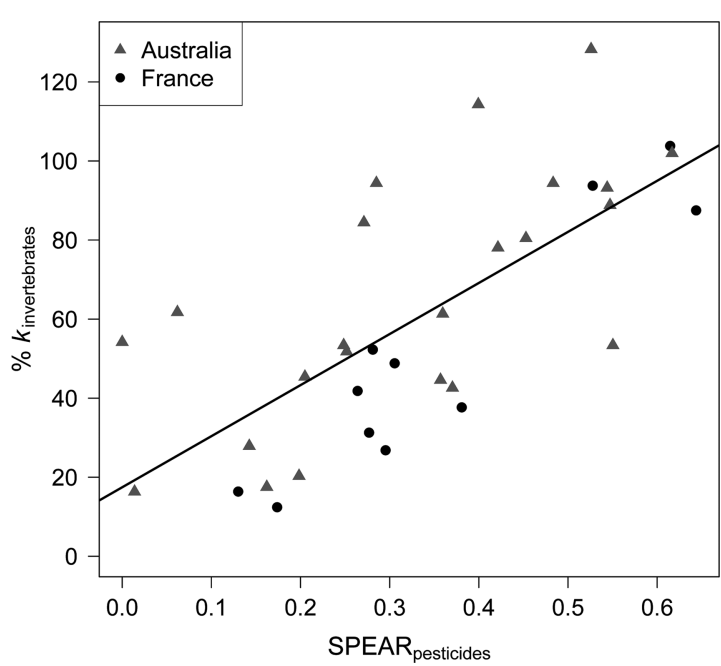

Figure 3. Linear regression model for the relationship between $\mathrm{SPEAR}_{\text {pesticides }}$ and $\% k_{\text {invertebrate }}$ and for sampling sites from Brittany, France and Victoria, Australia. The linear model explained 51\% of the variation $(p<0.001, n=34)$. Note that the intercepts for data from Brittany and Victoria were significantly different $(p=0.02)$ in ANCOVA (see Results for details).

and Victoria were significantly different $(p=0.02)$, whereas the slopes exhibited no significant differences $(p=0.25)$. However, if the data of each region were autoscaled before ANCOVA, neither the intercepts $(p=0.89)$ nor slopes $(p=0.15)$ were significantly different.

\section{DISCUSSION}

Effect Thresholds for Macroinvertebrate Communities. In our analysis, pesticide effects on the abundance of sensitive invertebrates were found at TUs for D. magna below 0.01 . Concentrations related to the safety factor incorporated in the UP resulted in a $27 \%$ to $61 \%$ decline in the abundance of sensitive taxa, depending on the presence of forested upstream sections and which minimum TU was selected in modeling (Figure 1, Figure S1). Similarly, both of the latter factors (presence of forested upstream sections and minimum TU) influenced the estimated effect concentrations (Table 2) and the concentration at which significant differences to reference sites occurred. The models with a lower minimum TU exhibited a better fit in terms of the BIC compared to models with a higher minimum TU (Table S2). Nevertheless, more field data in the log TU range of -3 to -5 would be needed to substantiate a selection between both minimum TUs. The effect threshold was determined to be approximately 1 to 1.5 orders of magnitude lower ( $\log \mathrm{TU}$ of -3 to -3.6 ) than the safety factor of the UP. However, field studies and results from the joint analysis of studies with differing methodologies are subject to random and systematic uncertainties that can lead to wider confidence bands or bias in the dose-response models and would consequently affect the derived effect threshold. Several uncertainties were identified as random (Supporting Information Table S4) and presumably resulted in wider confidence bands of the fitted dose-response curves (Figure 1, Figure S1) as for example, the joint analysis of data obtained from different countries, years and pesticide sampling methods (Table1). Nevertheless, there were no significant differences between the studies regarding the relationship of SPEAR $R_{\text {pesticides }}$ and TU (linear model for studies with pesticide gradients of at least $1 \log$ unit in terms of TU, $p=0.23, n=58)$. Moreover, some of the variation in the relationship between pesticide toxicity and $\mathrm{SPEAR}_{\text {pesticides }}$ may result from differences in the dose-response relationship of individual compounds i.e. concentrations of different compounds relating to for example $1 / 100$ of their EC50 for D. magna may exert different effects on the abundance of sensitive taxa. Two studies found that the toxicity of a range of different organic toxicants also explained between $68 \%$ and $87 \%$ of the variance in terms of $\mathrm{r}^{2}$ in SPEAR, ${ }^{24,26,36}$ suggesting that the use of toxic units for $D$. magna as benchmark for the toxicity of different organic toxicants is adequate and that the associated uncertainty is of minor importance.

Two sources of uncertainty could result in a systematic bias in the derived effect threshold. First, the underestimation of pesticide toxicity due to underestimated pesticide concentrations or the nonmeasurement of ecotoxicologically relevant compounds would lead to a left shift of the dose-response curve and consequently a decrease in the effect threshold. However, underestimation of the real concentrations by a factor of 10 to 100 would be required in order to yield similar effect thresholds than incorporated in the UP. We consider an underestimation of this order of magnitude as highly unlikely given that the field studies employed sampling techniques especially targeted at capturing episodic pesticide exposures (Table 1). Although the sampling techniques varied due to differences in the pesticides monitored and regional conditions, the relationship between pesticide toxicity in terms of TU and SPEAR $_{\text {pesticides }}$ was not significantly different between the studies (see above). Furthermore, the concentrations responsible for the estimated TUs are in agreement with studies monitoring pesticide runoff with 15 -min or 1-h resolution in single agricultural streams. Two studies in Central Europe found peak herbicide concentrations of $2.5^{37}$ and $3.5 \mu \mathrm{g} / \mathrm{L},{ }^{38,39}$ and a study in South Africa found insecticide concentrations ranging from 0.2 to $2.9 \mu \mathrm{g} / \mathrm{L}$ in runoff events. ${ }^{40}$ In the studies with relevant pesticide contamination $(\mathrm{TU}>-4)$ included in our meta-analysis, peak insecticide concentrations were in the range between 0.3 and $1.2 \mu \mathrm{g} / \mathrm{L}$ (i.e., Brittany, France $=0.7 \mu \mathrm{g} /$ $\mathrm{L}$; Victoria, Australia $=1.2 \mu \mathrm{g} / \mathrm{L} ;$ Denmark $=0.3 \mu \mathrm{g} / \mathrm{L}$; Germany $=0.5 \mu \mathrm{g} / \mathrm{L})$. Moreover, it would not be expected that all compounds are underestimated in equal measure and underestimation should therefore increase the variability in pesticide toxicity that relied on different compounds in all included studies. In fact, all individual studies exhibited a very good fit (all $\mathrm{r}^{2}$ from linear models between 0.62 and 0.68 ) of pesticide toxicity with the respective biotic end point. Finally, laboratory toxicity experiments with single pyrethoid, organochlorine and organophosphate insecticides demonstrated that chronic population effects can occur 3 to 4 orders of magnitude below acute toxicity concentrations. ${ }^{41-44}$ This means that effects may be expected above a TU for D. magna of -4 or -3 , 
which is in line with the effect thresholds derived here. Overall, although we agree that methodical advancements in the characterization of episodic pesticide exposure are desirable and that underestimation of true peak concentrations to a certain degree may occur in the field with currently available sampling techniques, we consider it highly unlikely that true pesticide concentrations were 1 or 2 orders of magnitude higher.

Second, the response of the SPEAR index to a confounding factor that is highly correlated with pesticide toxicity would lead to a decrease in effect thresholds (Supporting Information Table S4). The original studies included in our analysis (Table 1) and two recent studies ${ }^{45,46}$ identified the toxicity of the observed stressor as the most important explanatory variable for the respective version of the SPEAR index, whereas 8 and 9 respectively measured confounding factors exhibited no explanatory power for SPEAR. Furthermore, three studies

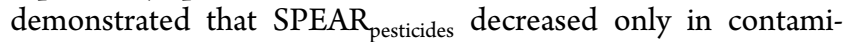
nated sites and after beginning of the pesticide application period, ${ }^{7,17,47}$ reinforcing that pesticides are the culprit because other agricultural stressors such as eutrophication or sedimentation are present throughout the year. Moreover, SPEAR $_{\text {pesticides }}$ showed no response to physicochemical, habitat or landscape variables in reference sites. ${ }^{18,48}$ Finally, albeit one

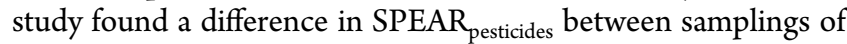
heterogeneous and homogeneous habitats in 13 streams in agricultural areas, there was nevertheless a strong relationship between SPEAR pesticides $_{\text {and }}$ TU for each habitat type $\left(r^{2}=0.68\right.$ and 0.6 in heterogeneous and homogeneous habitats, respectively). ${ }^{49}$ Overall, there is only low uncertainty that the indicated effects were not due to pesticide toxicity. Higher uncertainty remains regarding the mechanisms causing the observed effects of pesticides in the field. A review of mesocosm studies regarding effects of carbamate, pyrethroid and organophosphate insecticides suggested that a $\log$ TU for D. magna of -2 would be protective for individual insecticides in the field. ${ }^{3}$ Beside methodical ${ }^{46}$ (and see debate ${ }^{50,51}$ ) reasons, the difference between the field and mesocosm studies could result from different community composition, ${ }^{52}$ repeated exposures, pesticide mixtures ${ }^{5,53}$ and the joint effects of different stressors, ${ }^{4,46,54,55}$ all of which can enhance the effects of pesticides and are rarely considered in mesocosms. Moreover, chronic long-term effects on merolimnic insects occurring at concentrations related to a $\mathrm{TU}$ of -3 to -4 as outlined above $^{41-44}$ may not be detected in mesocosm studies, which rarely exceed a study period of several months. However, studies with a high temporal and spatial resolution would be needed to clarify the mechanisms in the field [see ref 56]. Overall, we suggest that there is low uncertainty that our derived effect threshold for effects of pesticides on macroinvertebrate communities is too low and we therefore conclude that the safety factor related to D. magna incorporated in the EU Uniform Principles for single pesticides is not protective for freshwater ecosystems, though the mechanisms should be elucidated in future studies.

Effects Thresholds for the Ecosystem Function of Leaf Breakdown. The relationship between the community structure in terms of SPEAR pesticides and the percentage of invertebrate leaf breakdown was linear in Brittany, France and Victoria, Australia (Figure 3). This means that of several suggested links between the community structure and ecosystem functions (see Introduction), pesticide effects on the abundance of sensitive macroinvertebrates seem to translate to a similar effect on the breakdown rate of leafs by invertebrates. Hence, in these regions is no greater tolerance of this important ecosystem function to pesticide contamination and the effect thresholds for the abundance of SPEAR taxa may also apply. Given that regional case studies on the relationship between pesticides and ecosystem functions are scarce, this result may not hold for different ecosystem functions, ${ }^{8}$ and other regions. In fact, no plausible relationship between SPEAR $_{\text {pesticides }}$ and the invertebrate leaf breakdown rate was found for the Danish sites. Similarly, the original study on the Danish streams only reported a statistically significant relationship between pesticide toxicity and microbial leaf breakdown but not with invertebrate leaf breakdown. ${ }^{23}$ Hence, although pesticide toxicity lead to community change

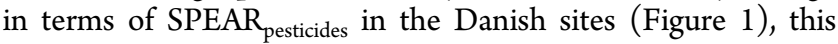
did not translate to effects on the ecosystem function of leaf breakdown. This can be explained by the domination of the shredder community by Gammarus pulex, which is a rather tolerant species due to its ecological traits and is consequently not classified as SPEAR. ${ }^{23}$ In fact, the density of Gammarus pulex was significantly correlated only to the leaf breakdown rate $(p=0.02$, test for Pearson correlation, $n=13)$. Thus, the effect threshold for the invertebrate leaf breakdown presumably depends on the composition of the shredder community, and if non-SPEAR taxa such as Gammarus pulex dominate, there may be functional redundancy up to a certain threshold before pesticides affect invertebrate leaf breakdown. Finally, the question is to which extent a temporal difference between pesticide application and leaf input from deciduous trees affects the relationship between pesticide-driven structural changes and invertebrate leaf breakdown (see ref 57). The studies in France and Denmark were conducted in the period of peak insecticide application in these regions, which precedes the period of main input of leafs (late autumn) by several months. Although it is known that community alterations can persist over months, ${ }^{7,20}$ it remains to be shown that the invertebrate leaf breakdown is affected outside of the main season of pesticide application. However, for streams receiving a relatively constant leaf input from evergreen forests (e.g., Australian streams), ${ }^{58}$ the influence of seasonality on the effects of pesticides on invertebrate leaf breakdown should be of minor importance.

Relevance for Ecological Risk Assessment of Aquatic Ecosystems. The thresholds obtained in our study may be relevant for pesticides and other organic compounds where macroinvertebrates represent the most sensitive group of taxa. In a study on the concentrations of 331 organic toxicants in large rivers of North Germany, invertebrates were considered as most sensitive for 110 compounds, among them many insecticides and fungicides, whereas algae and fish represented the most sensitive group for 142 and 79 compounds, respectively. ${ }^{59}$ Another study reported that invertebrates were most sensitive for 225 organic toxicants, whereas algae and fish exhibited highest sensitivity for 158 and 104 organic toxicants, respectively. ${ }^{36}$ In this study, an effect threshold of $1 / 1000$ of the acute EC50 for D. magna was suggested for the derivation of environmental quality standards (EQS) for river basin specific pollutants, based on an analysis of macroinvertebrate biomonitoring and chemical monitoring data. Hence, effect thresholds for macroinvertebrates would also be protective of other aquatic organisms for a wide range of compounds. The relatively good relationship between pesticide toxicity in terms of TU and SPEAR in our study is remarkable, considering that 
the macroinvertebrate data originated from different regions in Europe, Siberia and Australia and the low explanatory power for biotic end points often seen in ecological meta-analyses. ${ }^{60}$ Our study therefore supports the use of trait-based approaches in risk assessment to identify the impact of anthropogenic stressors on a continental or even global scale. ${ }^{11,16}$

Without knowing the temporal and spatial dimension of the reduction in the abundance of sensitive macroinvertebrate populations in this study, it is not possible to decide whether the observed effects on the communities were transient or longterm, defined as no complete recovery until the spraying period in the consecutive year. In the latter case, the effects would be unacceptable for the requirements of the $\mathrm{EU}$ directive for the placement of plant protection products on the market. ${ }^{2,61}$ However, we suggest that current exposure of freshwater ecosystems to pesticides may be unacceptable for the requirements of this and other EU directives. First, one field study showed long-term effects, that is, that no recovery of the communities occurred until the prespraying period of the following year. ${ }^{7}$ Second, given that pesticides are widely applied in agriculture, which represents the dominant land use in the EU and elsewhere, and that pesticides frequently occur in streams and rivers in concentrations above effect thresholds, ${ }^{20}$ the associated reduction in the abundance of sensitive taxa may lead to losses in biodiversity on a regional scale ( $\gamma$-diversity) as also indicated by other studies. ${ }^{62,63}$ Since a recent EU Directive requires that the risks for biodiversity from pesticides be minimized, ${ }^{64}$ more pesticide mitigation measures may be needed to comply with this Directive. Our study highlighted on the basis of a comprehensive data set that forested upstream sections can reduce adverse effects of pesticides on the macroinvertebrate community, especially under low pesticide contamination as indicated by higher effect thresholds (Table 2 ). Hence, together with other risk mitigation measures such as pesticide use reduction, buffer strips and vegetated treatment systems, ${ }^{22,65,66}$ the conservation and increase of landscape patches without agricultural disturbance may somewhat alleviate the effects of pesticides in aquatic ecosystems.

\section{ASSOCIATED CONTENT}

\section{S Supporting Information}

A figure with the relationship between pesticide toxicity and SPEAR $_{\text {pesticides }}$ for a minimum log TU of -5 , a table with the goodness of fit results for all models, a table with the parameters of the fitted dose-response models and a table giving sources of potential uncertainties. This material is available free of charge via the Internet at http://pubs.acs.org.

\section{AUTHOR INFORMATION}

\section{Corresponding Author}

*Telephone: ++49 (0) 6341 28031536. E-mail: senator@ ecotoxicology.de.

\section{Author Contributions}

Study design: R.B.S., P.C.O., B.J.K., M.B., M.L. Provision of data: R.B.S., P.C.O., J.R., M.B., M.L. Data analysis: R.B.S. Discussion and interpretation of results: all. Drafting of manuscript: R.B.S. Revising manuscript: R.B.S., M.B., B.J.K., P.C.O., M.L.

\section{Notes}

The authors declare no competing financial interest.

\section{ACKNOWLEDGMENTS}

The authors thank all persons involved in the field studies analysed in this paper. Mirco Bundschuh and five anonymous reviewers gave valuable comments that improved the quality of the manuscript. We are grateful to Sabine Duquesne for clarifying the legal situation for pesticide authorization. P.C.O. was financially supported through a Deutsche Forschungsgemeinschaft (DFG) postdoctoral fellowship (PAK 406/1). J.R. received funding from the Danish Research Council (RISKPOINT, Grant No 2104-07-0035). A visit by B.J.K. to Germany was funded by the University of Technology Sydney.

\section{REFERENCES}

(1) Millenium Ecosystem Assessment Ecosystems and Human Wellbeing: Synthesis; Island Press: Washington, DC, 2005.

(2) European Council Directive 91/414/EEC of 15 July 1991 concerning the placing of plant protection products on the market.

(3) Van Wijngaarden, R. P. A; Brock, T. C. M.; Van Den Brink, P. J. Threshold levels for effects of insecticides in freshwater ecosystems: A review. Ecotoxicology 2005, 14 (3), 355-380.

(4) Belden, J. B.; Gilliom, R. J.; Martin, J. D.; Lydy, M. J. Relative toxicity and occurrence patterns of pesticide mixtures in streams draining agricultural. Integr. Environ. Assess. Manage. 2007, 3 (1), 90100.

(5) Van den Brink, P. J.; Crum, S. J. H.; Gylstra, R.; Bransen, F.; Cuppen, J. G. M.; Brock, T. C. M. Effects of a herbicide-insecticide mixture in freshwater microcosms: Risk assessment and ecological effect chain. Environ. Pollut. 2009, 157 (1), 237-249.

(6) Townsend, C. R.; Uhlmann, S. S.; Matthaei, C. D. Individual and combined responses of stream ecosystems to multiple stressors. J. Appl. Ecol. 2008, 45 (6), 1810-1819.

(7) Liess, M.; von der Ohe, P. C. Analyzing effects of pesticides on invertebrate communities in streams. Environ. Toxicol. Chem. 2005, 24 (4), 954-965.

(8) Schäfer, R. B.; Bundschuh, M.; Rouch, D. A.; Szöcs, E.; von der Ohe, P. C.; Pettigrove, V.; Schulz, R.; Nugegoda, D.; Kefford, B. J. Effects of pesticide toxicity, salinity, and other environmental variables on selected ecosystem functions in streams and the relevance for ecosystem services. Sci. Total Environ. 2012, 415 (1), 69-78.

(9) Webster, J. R. Spiraling down the river continuum: stream ecology and the U-shaped curve. J. North Am. Benthol. Soc. 2007, 26 (3), 375-389.

(10) Sutherland, W. J.; Adams, W. M.; Aronson, R. B.; Aveling, R.; Blackburn, T. M.; Broad, S.; Ceballos, G.; Cote, I. M.; Cowling, R. M.; GA, D. A. F.; Dinerstein, E.; Ferraro, P. J.; Fleishman, E.; Gascon, C.; Hunter, M., Jr.; Hutton, J.; Kareiva, P.; Kuria, A.; Macdonald, D. W.; Mackinnon, K.; Madgwick, F. J.; Mascia, M. B.; McNeely, J.; MilnerGulland, E. J.; Moon, S.; Morley, C. G.; Nelson, S.; Osborn, D.; Pai, M.; Parsons, E. C.; Peck, L. S.; Possingham, H.; Prior, S. V.; Pullin, A. S.; Rands, M. R.; Ranganathan, J.; Redford, K. H.; Rodriguez, J. P.; Seymour, F.; Sobel, J.; Sodhi, N. S.; Stott, A.; Vance-Borland, K.; Watkinson, A. R. One hundred questions of importance to the conservation of global biological diversity. Conserv. Biol. 2009, 23 (3), $557-567$.

(11) Cadotte, M. W.; Carscadden, K.; Mirotchnick, N. Beyond species: Functional diversity and the maintenance of ecological processes and services. J. Appl. Ecol. 2011, 48 (5), 1079-1087.

(12) Kefford, B. J.; Schäfer, R. B.; Metzeling, L. Risk assessment of salinity and turbidity in Victoria (Australia) to stream insects' community structure does not always protect functional traits. Sci. Total Environ. 2012, 415 (1), 61-68.

(13) Van den Brink, P.; Alexander, A. C.; Desrosiers, M.; Goedkoop, W.; Goethals, P. L. M.; Liess, M.; Dyer, S. D. Traits-based approaches in bioassessment and ecological risk assessment: Strengths, weaknesses, opportunities and threats. Integr. Environ. Assess. Manage. 2011, 7 (2), 198-208. 
(14) Liess, M.; Schäfer, R. B.; Schriever, C. A. The footprint of pesticide stress in communities-Species traits reveal community effects of toxicants. Sci. Total Environ. 2008, 406 (3), 484-490.

(15) Poff, N. L. Landscape filters and species traits: Towards mechanistic understanding and prediction in stream ecology. J. North Am. Benthol. Soc. 1997, 16 (2), 391-409.

(16) Statzner, B.; Beche, L. A. Can biological invertebrate traits resolve effects of multiple stressors on running water ecosystems? Freshwat. Biol. 2010, 55, 80-119.

(17) Schäfer, R. B.; Caquet, T.; Siimes, K.; Mueller, R.; Lagadic, L.; Liess, M. Effects of pesticides on community structure and ecosystem functions in agricultural streams of three biogeographical regions in Europe. Sci. Total Environ. 2007, 382 (2-3), 272-285.

(18) von der Ohe, P. C.; Prüß, A.; Schäfer, R. B.; Liess, M.; Deckere, E. d.; Brack, W. Water quality indices across Europe - a comparison of the good ecological status of five river basins. J. Environ. Monit. 2007, 9, 970-978.

(19) Schäfer, R. B.; Pettigrove, V.; Rose, G.; Allinson, G.; Wightwick, A.; von der Ohe, P. C.; Shimeta, J.; Kühne, R.; Kefford, B. J. Effects of pesticides monitored with three sampling methods in 24 sites on macroinvertebrates and microorganisms. Environ. Sci. Technol. 2011, 45 (4), 1665-1672.

(20) Schäfer, R. B.; van den Brink, P. J.; Liess, M. Impacts of pesticides on freshwater ecosystems. In Ecological Impacts of Toxic Chemicals; Sanchez-Bayo, F., van den Brink, P., Mann, R. M., Eds.; Bentham: Bussum, NL, 2011.

(21) Friberg, N.; Lindstrom, M.; Kronvang, B.; Larsen, S. E. Macroinvertebrate/sediment relationships along a pesticide gradient in Danish streams. Hydrobiologia 2003, 494 (1-3), 103-110.

(22) Rasmussen, J. J.; Baattrup-Pedersen, A.; Wiberg-Larsen, P.; McKnight, U. S.; Kronvang, B. Buffer strip width and agricultural pesticide contamination in Danish lowland streams: Implications for stream and riparian management. Ecol. Eng. 2011, 37 (12), 19901997.

(23) Rasmussen, J. J.; Wiberg-Larsen, P.; Baattrup-Pedersen, A.; Monberg, R. J.; Kronvang, B. Impact of pesticides and natural stressors on leaf litter decomposition in agricultural streams. Sci. Total Environ. 2011, 416, 148-155.

(24) Beketov, M. A.; Liess, M. An indicator for effects of organic toxicants on lotic invertebrate communities: Independence of confounding environmental factors over an extensive river continuum. Environ. Pollut. 2008, 156 (3), 980-987.

(25) Sprague, J. B. Measurement of pollutant toxicity to fish, IIUtilizing and applying bioassay results. Water Res. 1970, 4 (1), 3-32.

(26) von der Ohe, P. C.; de Deckere, E.; Prüß, A.; Munoz, I.; Wolfram, G.; Villagrasa, M.; Ginebreda, A.; Hein, M.; Brack, W. Toward an integrated assessment of the ecological and chemical status of European river basins. Integr. Environ. Assess. Manage. 2009, 5 (1), $50-61$.

(27) Beketov, M. A.; Foit, K.; Schäfer, R. B.; Schriever, C. A.; Sacchi, A.; Capri, E.; Biggs, J.; Wells, C.; Liess, M. SPEAR indicates pesticide effects in streams-Comparative use of species- and family-level biomonitoring data. Environ. Pollut. 2009, 157, 1841-1848.

(28) Benfield, E. F. Decomposition of leaf material. In Methods in Stream Ecology; Hauer, F. R.; Lamberti, G. A., Eds.; Academic Press: San Diego, CA, 2007.

(29) Gessner, M. O.; Chauvet, E. A case for using litter breakdown to assess functional stream integrity. Ecol. Appl. 2002, 12 (2), 498-510.

(30) Statzner, B.; Bis, B.; Dolédec, S.; Usseglio-Polatera, P. Perspectives for biomonitoring at large spatial scales: A unified measure for the functional composition of invertebrate communities in European running waters. Basic Appl. Ecol. 2001, 2, 73-85.

(31) Allan, J. D.; Castillo, M. M., Stream Ecology: Structure and Function of Running Waters. Springer: Dordrecht, the Netherlands, 2007.

(32) Ritz, C. Toward a unified approach to dose-response modeling in ecotoxicology. Environ. Toxicol. Chem. 2010, 29 (1), 220-229.

(33) Fox, J.; Weisberg, S. An R Companion to Applied Regression, 2nd ed.; Sage: Los Angeles, CA, 2011.
(34) R Development Core Team R: A language and environment for statistical computing, reference index version 2.13.1. www.r-project.org (October 5 2011).

(35) Ritz, C.; Streibig, J. C. Bioassay analysis using R. J. Stat. Software 2005, 12 (5), 1-22.

(36) von der Ohe, P. C.; Dulio, V.; Slobodnik, J.; De Deckere, E.; Kühne, R.; Ebert, R.-U.; Ginebreda, A.; De Cooman, W.; Schüürmann, G.; Brack, W. A new risk assessment approach for the prioritization of 500 classical and emerging organic microcontaminants as potential river basin specific pollutants under the European Water Framework Directive. Sci. Total Environ. 2011, 409 (11), 2064-2077.

(37) Wittmer, I. K.; Bader, H. P.; Scheidegger, R.; Singer, H.; Luck, A.; Hanke, I.; Carlsson, C.; Stamm, C. Significance of urban and agricultural land use for biocide and pesticide dynamics in surface waters. Water Res. 2010, 44 (9), 2850-2862.

(38) Leu, C.; Singer, H.; Stamm, C.; Muller, S. R.; Schwarzenbach, R. $\mathrm{P}$. Simultaneous assessment of sources, processes, and factors influencing herbicide losses to surface waters in a small agricultural catchment. Environ. Sci. Technol. 2004, 38 (14), 3827-3834.

(39) Leu, C.; Singer, H.; Stamm, C.; Muller, S. R.; Schwarzenbach, R. P. Variability of herbicide losses from 13 fields to surface water within a small catchment after a controlled herbicide application. Environ. Sci. Technol. 2004, 38 (14), 3835-3841.

(40) Schulz, R. Rainfall-induced sediment and pesticide input from orchards into the Lourens River, Western Cape, South Africa: Importance of a single event. Water Res. 2001, 35, 1869-1876.

(41) Beketov, M. A.; Liess, M. Acute contamination with esfenvalerate and food limitation: Chronic effects on the mayfly, Cloeon dipterum. Environ. Toxicol. Chem. 2005, 24 (5), 1281-1286.

(42) Liess, M. Population response to toxicants is altered by intraspecific interaction. Environ. Toxicol. Chem. 2002, 21 (1), 138142.

(43) Liess, M.; Schulz, R. Chronic effects of short-term contamination with the pyrethroid insecticide fenvalerate on the caddisfly Limnephilus lunatus. Hydrobiologia 1996, 324 (2), 99-106.

(44) Schulz, R.; Liess, M. Chronic effects of low insecticide concentrations on freshwater caddisfly larvae. Hydrobiologia 1995, 299, 103-113.

(45) Schäfer, R. B.; Kefford, B.; Metzeling, L.; Liess, M.; Burgert, S.; Marchant, R.; Pettigrove, V.; Goonan, P.; Nugegoda, D. A trait database of stream invertebrates for the ecological risk assessment of single and combined effects of salinity and pesticides in South-East Australia. Sci. Total Environ. 2011, 409 (11), 2055-2063.

(46) Liess, M.; Beketov, M. Traits and stress: keys to identify community effects of low levels ot toxicants in test systems. Ecotoxicology 2011, 20 (6), 1328-1340.

(47) Schriever, C. A.; Hansler-Ball, M.; Holmes, C.; Maund, S.; Liess, M. Agricultural intensity and landscape structure: influences on the macroinvertebrate assemblages of small streams in northern Germany. Environ. Toxicol. Chem. 2007, 26 (2), 346-357.

(48) Schletterer, M.; Füreder, L.; Kuzovlev, V. V.; Beketov, M. A. Testing the coherence of several macroinvertebrate indices and environmental factors in a large lowland river system (Volga River, Russia). Ecol. Indic. 2010, 10 (6), 1083-1092.

(49) Rasmussen, J. J.; Wiberg-Larsen, P.; Baattrup-Pedersen, A.; Friberg, N.; Kronvang, B. Stream habitat structure influences macroinvertebrate response to pesticides. Environ. Pollut. 2012, 164, 142-149.

(50) Van den Brink, P. J.; Ter Braak, C. J. Response to "Traits and stress: keys to identify community effects of low levels of toxicants in test systems" by Liess and Beketov (2011). Ecotoxicology 2012, 21 (2), 297-9.

(51) Liess, M.; Beketov, M. A. Rebuttal related to "Traits and stress: Keys to identify community effects of low levels of toxicants in test systems" by Liess and Beketov (2011). Ecotoxicology 2012, 21 (2), $300-3$.

(52) Beketov, M.; Schäfer, R. B.; Marwitz, A.; Paschke, A.; Liess, M. Long-term stream invertebrate community alterations induced by the 
insecticide thiacloprid: Effect concentrations and recovery dynamics. Sci. Total Environ. 2008, 405, 96-108.

(53) Lydy, M. J.; Austin, K. R. Toxicity assessment of pesticide mixtures typical of the Sacramento-San Joaquin Delta using Chironomus tentans. Arch. Environ. Contam. Toxicol. 2005, 48 (1), $49-55$.

(54) Holmstrup, M.; Bindesbol, A. M.; Oostingh, G. J.; Duschl, A.; Scheil, V.; Kohler, H. R.; Loureiro, S.; Soares, A. M.; Ferreira, A. L.; Kienle, C.; Gerhardt, A.; Laskowski, R.; Kramarz, P. E.; Bayley, M.; Svendsen, C.; Spurgeon, D. J. Interactions between effects of environmental chemicals and natural stressors: A review. Sci. Total Environ. 2010, 408 (18), 3746-62.

(55) Heugens, E.; Hendriks, A.; Dekker., T.; Van Straalen, N. M.; Admiraal, W. A review of the effects of multiple stressors on aquatic organisms and analysis of uncertainty factors for use in risk assessment. Crit. Rev. Toxicol. 2001, 31 (3), 247-284.

(56) Liess, M.; Schulz, R. Linking insecticide contamination and population response in an agricultural stream. Environ. Toxicol. Chem. 1999, 18, 1948-1955.

(57) Bergfur, J. Seasonal variation in leaf-litter breakdown in nine boreal streams: implications for assessing functional integrity. Fundam. Appl. Limnol. 2007, 169 (4), 319-329.

(58) Tyler, P.; Williams, B. Lakes and Rivers. In Ecology: An Australian Perspective; Attiwill, P., Wilson, B., Eds.; Oxford University Press: South Melbourne, Australia, 2003.

(59) Schäfer, R. B.; von der Ohe, P.; Kühne, R.; Schüürmann, G.; Liess, M. Occurrence of 331 organic pollutants in four rivers of North Germany between 1994 and 2004 and risk assessment for algae, invertebrates and fish. Environ. Sci. Technol. 2011, 45 (14), 61676174.

(60) Moller, A. P.; Jennions, M. D. How much variance can be explained by ecologists and evolutionary biologists? Oecologia 2002, 132 (4), 492-500.

(61) European Commission Guidance Document Sanco/3268/2001 rev.4 on Aquatic Ecotoxicology in the context of the Directive 91/414/ EEC..

(62) Gibbs, K. E.; Mackey, R. L.; Currie, D. J. Human land use, agriculture, pesticides and losses of imperiled species. Divers. Distrib. 2009, 15 (2), 242-253.

(63) Geiger, F.; Bengtsson, J.; Berendse, F.; Weisser, W. W.; Emmerson, M.; Morales, M. B.; Ceryngier, P.; Liira, J.; Tscharntke, T.; Winqvist, C.; Eggers, S.; Bommarco, R.; Part, T.; Bretagnolle, V.; Plantegenest, M.; Clement, L. W.; Dennis, C.; Palmer, C.; Onate, J. J.; Guerrero, I.; Hawro, V.; Aavik, T.; Thies, C.; Flohre, A.; Hanke, S.; Fischer, C.; Goedhart, P. W.; Inchausti, P. Persistent negative effects of pesticides on biodiversity and biological control potential on European farmland. Basic Appl. Ecol. 2010, 11 (2), 97-105.

(64) European Commission Directive 2009/128/EC of the European Parliament and of the Council of 21 October 2009 establishing a framework for Community action to achieve the sustainable use of pesticides.

(65) Reichenberger, S.; Bach, M.; Skitschak, A.; Frede, H. G. Mitigation strategies to reduce pesticide inputs into ground- and surface water and their effectiveness; A review. Sci. Total Environ. 2007, 384 (1-3), 1-35.

(66) Stehle, S.; Elsaesser, D.; Gregoire, C.; Imfeld, G.; Passeport, E.; Payraudeau, S.; Schäfer, R. B.; Tournebize, J.; Schulz, R. Pesticide Risk Mitigation by Vegetated Treatment Systems: A Meta-analysis. J. Environ. Qual. 2011, 40 (4), 1068-1080. 